\title{
Primary Health Care and Family Medicine
}

Mohammed Wael Daboul* and Zaid Al-Faham

Mohammed Wael Daboul, Daboul Medical Laboratory, Damascus University, Damascus, Syrian Arab Republic

\section{Definition of Primary Health Care}

Practical, scientifically sound, and socially acceptable method and technology; universally accessible to all in the community through their full participation; at an affordable cost; and geared toward selfreliance and self determination (WHO \& UNICEF, 1978).

Primary health care is primary care applied on a population level. As a population strategy, it requires the commitment of governments to develop a population-oriented set of primary care services in the context of other levels and types of services.

Primary Health Care exists to provide high quality and cost effective promotive, preventive, curative and rehabilitative health care services for the community, in a comprehensive bio-psycho-social approach in line with international standards.

\section{Primary Care}

Primary Care is the provision of integrated, accessible health care services by clinicians who are accountable for addressing a large majority of personal health care needs, developing a sustained partnership with patients, and practicing in the context of family and community (1996 IOM Report on the Future of Primary Care) [1].

Primary Health care is one of the first levels of contact of individuals, families, \& community with the national health system in many countries. It is a way of achieving health for all. It should be conceived as an integral part of any country's plan for socioeconomic development.

A call for transformation of health services into family medicine based services, was emphasized by WHO in lieu with the international, regional institutions trends.

\section{Characteristics of Family Medicine/General Practice}

- Seek appropriate consultation when indicated.

- Provide continuity of care throughout the patient's lifetime.

- Represents a synthesis of knowledge from other medical disciplines plus contributions from Family Medicine.

- View the whole patient as a unique individual as a person.

- Identify the patient's problems within the context of family, environment and culture.

- Manage the majority of these problems - especially those which occur frequently.

- Counsel \& promote health education (patient and peers).

- Mindful of the cost effectiveness related PHC services.

Main Challenges faced by the primary health systems in devastated locations in EMR

- Poverty \& lack of access to basic services.

- Programs sustainability.
- Insufficient Political commitment.

- Weak linkages between PHC and mobilized community.

- Inadequate distribution of resources (human and non-human).

- Deteriorated physical infrastructure- water-sewage systems \& environmental degradation [2].

- Limited institutional and human resources capacity building, and lack of an electronic health information system.

- Moving obstacles from hospital oriented health system to primary health care (health professionals, community, etc.).

- Inadequate care continuity - personnel, pathway, appointment [3].

\section{Social determinants of health}

The social determinants of health refer to both specific features and pathways by which societal conditions affect health and that potentially can be altered by informed action [4]

\section{SDH in Conflict and post-conflict emergencies}

Conflict affects the most vulnerable, exposes fault lines in society. It is Likely to increase inequities between those who can, leave and those who cannot and are forced to stay. Those last, lose major parts of human rights: security, food, shelter, social interaction, health care etc. Conflicts are always associated with breaches of medical neutrality and so far progression from stress to distress and disease [5].

\section{Equity in health and health services}

It is the absence of systematic and potentially remediable differences in one or more aspects of health across population groups defined geographically, demographically, or socially.

Equity Research is not the same as Social Determinants Research.

- Social determinants research assumes an individual model of health.

- Equity research assumes a population model of health.

\section{CDC and PHC: mutual benefit}

- The control of communicable diseases plays a vital role in the achievement of "health for all".

*Corresponding author: Mohammed Wael Daboul, Daboul Medical Laboratory, Damascus University, Damascus, Syrian Arab Republic, E-mail: idaboul@scs-net.org

Received January 14, 2013; Accepted January 15, 2013; Published January 20 , 2013

Citation: Daboul MW, Al-Faham Z (2013) Primary Health Care and Family Medicine. J Gen Pract 1: e102. doi: 10.4172/2329-9126.1000e102

Copyright: (C) 2013 Daboul MW, et al. This is an open-access article distributed under the terms of the Creative Commons Attribution License, which permits unrestricted use, distribution, and reproduction in any medium, provided the original author and source are credited. 
- Integrating communicable diseases prevention and control programs with PHC is essential to ensure.

- Better access to prevention and treatment services.

- Equity in distribution of the services.

- Sustainability of services.

\section{Strengthening Communicable Diseases Control through PHC}

1. Case detection: District level lab technicians on detection of CD.

2. An effective drug supply and Standardized treatment: District center keeps and maintain $\mathrm{CD}$ records and provide necessary treatment.

3. Provision of vaccination: $\mathrm{PHC}$ centers are the main vaccination delivery points.

4. Monitoring and evaluation system: Keeping and maintaining diseases and immunization records.

\section{Contributing to health system strengthening through CD Control}

1. Building human capacity through basic training, periodic inservice training, supervision and follow-up.

2. Enhancing better utilization of human resources: multi-purpose health workers.

3. Improving community participation.

4. Immunization and Control of Vaccine-Preventable Disease [6].

\section{Linking immunization activities to $\mathrm{PHC}$}

1. Vaccination is basically provided through the PHC services.

2. Reaching Every District (RED) approach: emphasis on.

3. Reaching all villages with at least 4 times a year with regular routine immunization services.

4. With Fixed and/or Outreach and/or Mobile activities.

5. Optimizing utilization of available resources \& integrating with other PHC interventions.

6. Active community participation in planning immunization sessions, implementation, monitoring.

\section{HIV/AIDS achievements through CDC and PHC correlation} between 1990 \& 2008

Before 1990s: No strongly established national programmes and very strong stigma $\&$ discrimination was present.

After 2008: A clear improvement in the problem of stigma \& discrimination and national programmes in all countries of the region was established.

\section{Constraints and Challenges}

1. Communicable diseases still responsible for around one third of all deaths and one third of all illnesses in the EMR.

2. Almost all these deaths and illnesses are preventable.

3. The tools needed are well known.
4. Effective and equitable use of the available tools is facing major challenges.

5. Inadequate coverage of health care delivery services.

6. Difficult to reach population in certain areas with complex emergency.

7. Inadequate and rapid turnover of trained human resources.

8. Weak community participation.

9. Lack of coordination of NGOs (National Government Organizations) and involvement of the private sector.

Many achievements, have been attained. However Cutaneous Leishmania could be a challenging example presented as a model for Constraints in achievements in Syria and may be in other parts of the Mediterranean area.

In spite of the achievements, few undermined communicable diseases are spreading faster and they are almost becoming as an epidemic in certain parts of the EMR. As for an example, Cutaneous Leishmaniasis in Syria.

Cutaneous Leishmaniasis is an endemic disease in over 70 countries. The yearly incidence is estimated at $(2,000,000)$ cases. Residing in the mediterenian area, Aleppo city was historically known as a focal area for this disease [7]. Once in a while, new foci are discovered in close locations to the original ones [8]. Till the mid 80s of last century, most cases being acquired in Syria were located in Aleppo city and the surrounding suburban area. Since then, new cases have been discovered towards the southern of Aleppo (Tables 1 and 2). Since the year 2000, we came to observe cases of cutaneous Leishmania highly concentrated in Damascus city and the urban area (Table 3 and Figure 1).

Figure 1 diagram representing the Disease incidence in percentage

\begin{tabular}{|c|c|}
\hline Total number of patients & 1478 \\
\hline Number of females & 454 \\
\hline Number of males & 976 \\
\hline Number of undefined gender & 48 \\
\hline
\end{tabular}

Table 1: Total number of patients diagnosed with cutaneous leishmania between 2005 - 2009 in Syria.

\begin{tabular}{|c|c|c|}
\hline City & Number of patients & Region \\
\hline Hims & 7 & Middle \\
\hline Hama & 19 & Middle \\
\hline Lathikiyah & 7 & North West \\
\hline Al Hasaka & 7 & North East \\
\hline Idlib & 9 & North \\
\hline Ar rakka & 7 & East \\
\hline Al Suwaida & 5 & south \\
\hline Al Qamishli & 5 & North East \\
\hline Al Qunaitirah & 6 & South \\
\hline Banias & 6 & North West \\
\hline Al Sheikh Mountain & 1 & North West \\
\hline Jablah & 3 & South \\
\hline Daraa & 19 & East \\
\hline Deir Al Zur & 7 & west \\
\hline Tartus & 6 & North \\
\hline Aleppo & 33 & South \\
\hline Unclassified & 71 & \\
\hline Damascus & 1261 & \\
\hline
\end{tabular}

Table 2: Distribution of identified cases according to the regions in Syria. 


\begin{tabular}{|c|c|c|c|c|}
\hline Region & City & Number of patients & Total Number & Percentage \\
\hline Middle & Hims & 7 & \multirow{2}{*}{26} & \multirow{2}{*}{$1.76 \%$} \\
\hline Middle & Hama & 19 & & \\
\hline East & Al Hasaka & 7 & \multirow{4}{*}{26} & \multirow{4}{*}{$1.76 \%$} \\
\hline East & Ar rakka & 7 & & \\
\hline East & Al Qamishli & 5 & & \\
\hline East & Deir Al Zur & 7 & & \\
\hline West & Jablah & 3 & \multirow{4}{*}{22} & \multirow{4}{*}{$1.5 \%$} \\
\hline West & Banias & 6 & & \\
\hline West & Tartus & 6 & & \\
\hline West & Lathikiyah & 7 & & \\
\hline South & Al Suwaida & 5 & \multirow{4}{*}{31} & \multirow{4}{*}{$2 \%$} \\
\hline South & $\begin{array}{l}\text { Al Sheikh } \\
\text { Mountain }\end{array}$ & 1 & & \\
\hline South & Al Qunaitirah & 6 & & \\
\hline South & Daraa & 19 & & \\
\hline North & Aleppo & 33 & \multirow{2}{*}{42} & \multirow{2}{*}{$2.8 \%$} \\
\hline North & Idlib & 9 & & \\
\hline \multirow[t]{2}{*}{ South } & Damascus & 1261 & & $85.3 \%$ \\
\hline & Unclassified & 71 & & $4.8 \%$ \\
\hline
\end{tabular}

Table 3: The Disease incidence according to the region.

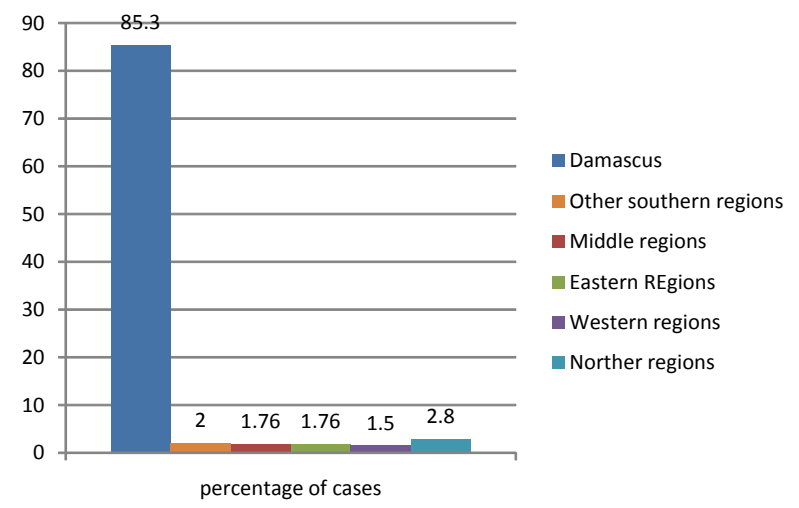

Figure 1: Representing the Disease incidence in percentage according to the region.

according to the region. The disease is caused by the Leishmania parasite, which is transmited by an infected sand fly in its promastigote form. During its meal, the sandfly transmits the promastigote into the victom skin, where it pentrates the skin layers. There, it loses its flagella. The parasite then, is phagocytosed by the macrophages and transformes into the amastigote form. The amastigote form multiplies within the macrophage, multinucleated giant cells, Langrhanse cells and the dendritic cells in the skin tissues [9]. Residing in the macrophage, the amastigote form is considered an obligatory intracelluler parasite [10]. The lesion appears in the skin as a dirty ulcer with volcanic edges [11]. It expands reaching 3-4 cm in diameter. Towards healing, the lesion shrinks, terminating with a small scar which lasts for lifelong [12]. The lesion may be manifested in one or two locations of the skin and rarely, the infection may be seen at more than two different locations in the same patient [13]. With leishmania infection, the infected patient develops a permanent immunity.

Lack of the disease control and the fast spread of the disease towards becoming an epidemic is an example of the challenges for PHC program in EMR.

Going back to the constraints and challenges presented above it is recognized that with regard to Cutaneous leishmania disease specifically:

1. This illness is almost preventable by controlling both the sand fly vectors (Phlebotomus sp and Lutzomyia sp) and its human or mammalian host.

2. The tools needed are well known: Controlling the victor sand fly growth and multiplication is achieved by controlling the living conditions and restoration of the damp places in the zoonotic foci, where the victor can survive, or by eradication of the victor itself. Treating the patient is achievable through the PHC and family medicine measures by first diagnosis of the disease with the laboratory personal and then treatment implimentation by family medicine team work

As for the other challanges: 3-4-5-6-7 and 8: That there is a shortage in service delivery in case of cutaneous leishmania due to the upper constrains is a fact. However, one important factor to shed the light on, is the emphases on the role of Laboratory Medicine in diagnosing and identifying both the disease and the causing factor. In addition to that, no one could under estimate the achievements of the laboratory medicine for PHC through both the discovery and invention of new techniques and practical methods for detecting and identifying the causing factor for different communicable diseases. In case of cutaneous leishmania, as for an example, a broad study of the disease was done [14]. Many papers in that regard were presented some of them published in EMR magazine [15]. Those studies came with new diagnostic features for the microscopic smear method which could be applied for fast and easy diagnosis [16]. Unfortunately since the papers publication, no further follow up or any measures were taken. This of course can cause a delay toward controlling the disease and may contribute sometimes to the exaggeration and the fast spread of it. The importance of the discovery in that regard is that new cytomorphologic figures are found in case of cutaneous leishmania which could be of very important diagnostic values. If those figures were considered, the sensitivity of the microscopic method in detecting the parasite will be dramatically elevated from maximum $60 \%$ up to a $100 \%$, and the specificity is elevated as well. Considering those findings on time, could be of importance in closing some of the gabs of constraints and challenges that have been mentioned above, especially with the favorable cost effectiveness of the discovered methods and the easiness of human resources to be trained with the procedure. If the newly discovered diagnostic methods were considered and applied, an adequate coverage of health care delivery services with regard to laboratory testing is easily achieved. And due to the procedure simplicity, it could be very easy to reach population in certain areas with complex emergency. Being a cheap procedure the community participation is most likely to be strong.

\section{Strategic Innovation: "Community-based initiative"}

There is a true need to go for a phrase that can be shared by all. Setting a clear goal is the key. This goal reflects a paradigm shift of health authorities (that people themselves could be relied upon). It is valuable to give more importance to social measure and integrate technical with social measure, a process innovation that enables people to take actions in aspects of health matters. E.g. prevention, promotion, treatment, rehabilitation, health security. In that matter it is of importance to assign roles of various players accordingly. Enhancing leadership means people's leadership which will hopefully overcome the resistance to change [17]. This Strong capacity and leadership must be at all levels:

- Scale up community-based interventions based with trained community workers. 
- Full involvement of the private sector and NGOs.

- Functional inter-sectoral mechanism.

- Integration between different programmes specially in the cross cutting issues.

Let's work together! We can make the difference.

\section{Evidence for Family Medicine}

- Family Medicine training resulted in less referral and ones of higher quality in Thailand.

- Faculty family physicians had improved continuity of care, communications and enablement when compared with general doctors and residents in Thailand.

- Teamwork within PHC is associated with better health outcomes and rewarding professional experience in the US.

- Research suggests that primary care teams with better cohesiveness leads to better patient health care outcomes and patient satisfaction.

- Review study suggests that trained nurses can achieve as good health outcomes for patients as doctors.

- Female health workers in Pakistan have been successfully trained in primary care and reduced infant and child mortality.

- Community-based primary care workers trained in psychological therapy improved rates of depression among mothers in rural Pakistan.

- Health workers with a shorter duration of training performed as well as and often better than those with a longer training in assessing, classifying, and managing episodes of routine childhood illness.

\section{Primary health care oriented countries}

- Have more equitable resource distributions.

- Have health insurance or services that are provided by the government.

- Have little or no private health insurance.

- Have no or low co-payments for health services.

- Are rated as better by their populations.

- Have primary care that includes a wider range of services and is family oriented.

- Have better health at lower costs [18].

\section{Conclusion}

1. Primary Care (Personal Care) as a part of Primary Health Care (Community-oriented Primary Care) can improve health.

2. Family Medicine as a specialty of Primary Care can play an important role in delivering Community-oriented Primary Care.

3. Although the goal of developing a cadre of family doctors to participate and lead the advance in community-oriented. Primary Care is great, it is achievable.

4. Countries and regions should share their experiences and resources to achieve this goal.
5. Careful distribution of resources is important.

6. High technology medicine is important but low technology medicine gets the right patient to the right high technology at the right time.

7. Underestimation of the role of the laboratory medicine and the personal in PHC team work should be reconsidered.

8. Follow-up of the new discoveries of the techniques and procedures in medical technology fields for diagnosis, and their application must be undertaken more serious.

\section{References}

1. Montegut AJ (1978) The Power of Primary Care: Is Family Medicine the Solution?

2. Mohammad Assai, RA/CBI,WHO/EMRO (2008) Twenty Years Experiences of Community-based Initiatives in the Eastern Mediterranean Region 1st International PHC Conference Qatar, 1 - 4 November 2008.

3. Ghanim Alsheikh (2008) Health Workforce in PHC: Achievements and Short comings and the Way Forward . Qatar Primary health Care Conference 01-04 November 2008.

4. Krieger N (2001) A glossary for social epidemiology. J Epidemiol Community Health 55: 693-700.

5. Sameen Siddiqi, Susan Watts (2008) Social Determinants of Health in the Eastern Mediterranean Region. International Conference on Primary Health Care Doha, Qatar 1-4 November 2008.

6. Jaouad Mahjour, Trend Of Communicable Diseases In The EMR 1978-2008 Qatar Primary health Care Conference 01-04 November 2008.

7. Hepburn NC (2003) Cutaneous Leishmaniasis: An overview. J Postgrad Med 9: 50-54.

8. Laila Nimri, Radwan Soubani, Marina Gramiccia (2002) Leishmania species and zymodemes isolated from endemic areas of cutaneous Leishmaniasis in Jordan. Kinetoplastid Biol Dis 1: 7.

9. Vidyashankar C, Agrawal R (2006) Pediatric Leishmaniasis.

10. Campos MB, De Castro Gomes CM, de Souza AA, Lainson R, Corbett CE, et al. (2008) In vitro infectivity of species of Leishmania (Viannia) responsible for American cutaneous Leishmaniasis. Parasitol 103: 771-776.

11. Esterre P, Dedet JP, Frenay C, Chevallier M, Grimaud JA(1992) Cell population in the lesion of human cutaneous Leishmaniasis:a light microscopical, immunohistochemical and ultrastructural study. Virchows Archiv A Pathol Anat Histopathol 421: 239-247.

12. Derya Gumurdulu, Melek Ergin, Ilhan Tuncer, Soner Uzun, Hamdi Memisoglu (2004) Histopathological and clinical evaluation of the cutaneous Leishmaniasis in Southern Anatolia, Turkey. Aegean Pathology Journal 1: 57-61.

13. Saleem K, Ayaz B, Shaikh A (2007) Histological grading patterns in patients of cutaneous Leishmaniasis. J Coll Physicians Surg Pak 17: 650-653.

14. Mohammed wael Daboul (2012) Cutaneous Leishmaniasis- A New Concept LAP LAMBERT Academic Publishing 2012.

15. Daboul MW (2010) Role of Neutrophils role in cutaneous leishmania. Eas Mediterr Health J.

16. Daboul MW (2011) Application of the microscopic method in cutaneous leishmania diagnosis. Our Dermatol Online 2: 198-202.

17. Amorn Nondasuta (2008) STRATEGY for ENHANCING LEADERSHIP IN PRIMARY HEALTH CARE . Qatar-EMRO Primary Health Care Conference, Doha, Qatar, November 2008.

18. Barbara Starfield (2008) Equity in Health and Health Services Qatar-EMRO Primary Health Care Conference. Doha, Qatar. November 2008. 